\title{
A Chemotaxonomic Study of Cuticular Hydrocarbons on Epilachna indica (Family: Coccinellidae) from Sarawak
}

\author{
RIZOH BOSORANG ${ }^{*}$, ZAINI ASSIM $^{2} \&$ SULAIMAN HANAPI $^{1}$ \\ ${ }^{1}$ Department of Zoology, ${ }^{2}$ Department of Chemistry, Faculty of Resource Science and Technology, \\ Universiti Malaysia Sarawak, 94300 Kota Samarahan, Sarawak, Malaysia
}

\begin{abstract}
The chemical composition of cuticular hydrocarbons of adult Epilacnha indica (ladybird beetles), collected from Kota Samarahan, Kota Padawan and Lanjak-Entimau, Sarawak were analyzed by using a capillary gas chromatography-mass spectrometer (GC-MS). Cuticular hydrocarbons extracted from 18 samples of adult $E$. indica (comprise of 90 individuals). Over $95 \%$ of the hydrocarbon peak areas consist of chain lengths from $\mathrm{C}_{18}$ to $\mathrm{C}_{38}$. The proportions of $\mathrm{n}$-alkanes between three different localities are significantly difference, except for $\mathrm{n}$ dotriacontane and n-tetratriacontane. Comparison between Kota Samarahan and Kota Padawan samples revealed the significant different in hydrocarbon composition for even-numbered carbon n-alkanes ranging from $n$ - $\mathrm{C}_{18}$ to $n-\mathrm{C}_{38}$ except for $n-\mathrm{C}_{32}$ and $n-\mathrm{C}_{34}$. Several odd-numbered carbon n-alkanes such as $n-\mathrm{C}_{25}, n-\mathrm{C}_{27}, n-\mathrm{C}_{33}$ and $n$ $\mathrm{C}_{35}$ also showed significant difference in the composition between Kota Samarahan and Kota Padawan. Examination on components contributing to the differentiation of localities showed that $n-\mathrm{C}_{29}, n-\mathrm{C}_{33}$ and $n-\mathrm{C}_{36}$ were important in discriminating three different localities. Discriminant function analysis (DFA) successfully classified all samples into three correct groups in $100 \%$ of cases, with cross-validation resulted in an error of $7.7 \%$. Individuals from each locality were grouped in the range of $2.10-9.16 \%$ differences, with average of $43 \%$ different reflected between localities. E. indica samples collected from the forests containing simpler hydrocarbon pattern than samples collected around housing or industrial areas. Result showed that differences in microenvironment have influenced the composition and proportion of insect cuticular hydrocarbon. The finding reveals the potential of cuticular hydrocarbons profile to separate subpopulations of species.
\end{abstract}

Keywords: Epilachna indica, cuticular hydrocarbon, gas chromatography-mass spectrometer

\section{INTRODUCTION}

The chemotaxonomic significance of cuticular alkanes was demonstrated on several orders of insects including Isoptera (Haverty et al., 1991; Takematsu \& Yamaoka, 1997), Lepidoptera (Arsene et al., 2002), Hymenoptera (Abdalla et al., 2003; Martin \& Drijfhout, 2009; Nunes et al., 2010), Dictyoptera (Chapman et al., 1995), Diptera (Anyanwu et al., 2000), Orthoptera (Bounecheda et al., 2011; Chapman et al., 1995), Hemiptera (Juarez \& Fernandez, 2007) and others. Species-specificity of cuticular hydrocarbons also had been studied for coleopteran families including Tenerbrionidae (Lockey, 1988), Chrysomelidae (Nelson \&

*Corresponding author: rizohbosorang@gmail.com
Charlet, 2003), Curculionidae (Lapointe et al., 2004), Silphidae (Whitlow, 2003) and the Scolytidae (Page et al., 1990). Several studies discovered that majority of hydrocarbons found in insects cuticular were aliphatic hydrocarbon range from $\mathrm{C}_{23}$ to $\mathrm{C}_{47}$ with odd-numbered compounds predominated the composition (Arsene et al., 2002; Chapman et al., 2000; Haverty et al., 1996; Juarez \& Fernandez, 2007; Page et al., 1990). Three main hydrocarbon classes that have been identified in hydrocarbon mixtures namely, $n$-alkanes, alkenes and methylalkanes. n-alkane was considered as the most prevalent in the cuticular hydrocarbons mixture comprising more than 54\% (Whitlow, 2003), where $\mathrm{C}_{22}$ 
and $\mathrm{C}_{29}$ are the usual principal compound of $n$ alkane in insects (Soliday et al., 1974).

Woodrow et al. (2000) reported that cuticular hydrocarbons of Chyptotermes brevis (Isoptera) comprised of $29 \% n$-alkanes, while Chapman et al. (2000) found that $n$-alkanes occupied $40 \%$ to $60 \%$ of the total hydrocarbon extracted from Schistocerca spp. (Orthoptera). On the other hand, Harverty et al. (1996) reported that methylalkanes dominated the cuticular hydrocarbons composition in Coptotermes formosanus (Isoptera). These studies have shown that the types and abundance of cuticular hydrocarbons varied in different species of insects. Meanwhile, variation between two different geographically isolated populations is much higher ranged between 30-60\% (Brown et al., 2000). The high variation in population through ecological isolation may reflect to the process of speciation (Brown et al., 2000; Wilgenburg et al., 2011). It was also suggested that the variation in cuticular hydrocarbons composition among population of the same species reflected the genetic differences rather than environment factors (Brown et al., 1997).

If a cuticular wax is to be used as a basis of systematic studies of phytophagus insects, it is clearly essential to have an understanding of the extent to which cuticular hydrocarbon varies within a well-recognized species at subpopulation level. Furthermore, examination of cuticular hydrocarbon variation is a necessary step for further taxonomic, genetic and ecological studies of phytophagous insects, particularly ladybird beetle in these regions. This study examine the variation of cuticular hydrocarbon of $E$. indica for three different localities based on group of $n$-alkanes compound, in which could serve as basis for developing optimal sampling regimes for further examination of this beetle.

\section{MATERIALS AND METHODS}

\section{Species collection and Identification}

A total of 90 adult Ladybird beetles $E$. indica from Kota Padawan, Kota Samarahan and Lanjak-Entimau were collected using beating trays, comprise 30 individuals for each sampling location. The specimens were frozen at $-20^{\circ} \mathrm{C}$ before hydrocarbons extraction (Page et al., 1990), and were identified by comparing them with voucher specimens in the Universiti Malaysia Sarawak Zoology Museum and also by using identification keys of Tung (1983).

\section{Cuticular waxes extraction and analysis}

Cuticular hydrocarbon of 18 samples, comprising five (5) individuals of adult $E$. indica for each sample, were extracted by immersing specimens in $10 \mathrm{~mL}$ chloroform for 1 min (Chapman et al., 1995). The extract was then allowed to evaporate at room temperature until dry and then dissolved with $10 \mathrm{~mL}$ of $n$ hexane. Following this, the extract was placed on top of a glass column chromatography packed with $4 \mathrm{~cm}$ of activated Biosil A (silica gel, 100-200 mesh) following that of Page et al. (1990) and eluted with $20 \mathrm{~mL}$ of $n$-hexane. The eluent was collected in a $50 \mathrm{~mL}$ pearshaped flask, which then concentrated via a rotary evaporator, before evaporated to dryness under a stream of nitrogen, and finally dissolved in $50 \mu \mathrm{L} n$-hexane for Gas Chromatographic (GC) analysis. GC analysis was performed with a Shimadzu QP5000 PLUS.

\section{Compound Identification and Analysis}

Cuticular hydrocarbons extracted from 18 samples of adult E. indica were identified by comparing their GC retention times and mass fragmentation patterns of standard reference materials, the standard mixture of $n$-alkanes ranging from $\mathrm{C}_{9}$ to $\mathrm{C}_{34}$. The identified compounds were further confirmed by comparing their mass spectra with mass spectra standard library installed in the data system (computer), which provided by National Institute of Standards and Technology (NIST). Twenty one quantitative characters (Table 1), representing 21 types of $n$-alkanes compounds, were performed in SPSS 17.0 to estimate the similarity and dissimilarity of hydrocarbons compositions. Cluster analysis was carried out with the Squared Euclidean as the distance measure and the unweighted pair group average as the linkage rule.

\section{RESULTS}

Overall, hydrocarbons are made up over 95\% of the analyze peak areas detected by GC/MS 
in all 18 samples of cuticular wax E. indica. The cuticular hydrocarbons of $E$. indica were represented by normal alkanes, alkenes and methyl-branched alkanes. Group of $n$-alkanes and methyl alkanes dominated the hydrocarbon profile of $E$. indica, while double bond $n$ alkenes were detected in minute amount in all the samples examined. GC/MS analysis showed that each sample contained between 100-120 peaks in the chromatograms. However, only 70 compounds were considered as cuticular hydrocarbon profile of E. indica as those compounds were detected in all samples examined, while the other minor components were detected in few samples and represent in trace. Furthermore, only peak above $0.05 \%$ of the total area were considered for data analysis. However, the hydrocarbon ranged from $\mathrm{C}_{18}$ to $\mathrm{C}_{38}$ was constantly detected among individuals within the species (Figure 1).
Although differences in hydrocarbon composition within populations are relatively small, differences are greater between geographical populations. The magnitude of these differences is also clearly illustrated by $\mathrm{GC} / \mathrm{MC}$ analysis presented in Figure 1. Cuticular hydrocarbons pattern of samples from Kota Samarahan showed a more complex with a wider range compared to samples from Kota Padawan and Lanjak-Entimau. However, both Kota Samarahan and Kota Padawan population showed similar hydrocarbon chain series ranging from $\mathrm{C}_{18}$ to $\mathrm{C}_{38}$ although $n$ alkanes from $\mathrm{C}_{18}$ to $\mathrm{C}_{26}$ were found in small quantity in Kota Padawan. Cuticular hydrocarbon from Lanjak-Entimau samples contained a homologous series from $\mathrm{C}_{18}$ to $\mathrm{C}_{37}$ which is shorter from those two other samples.
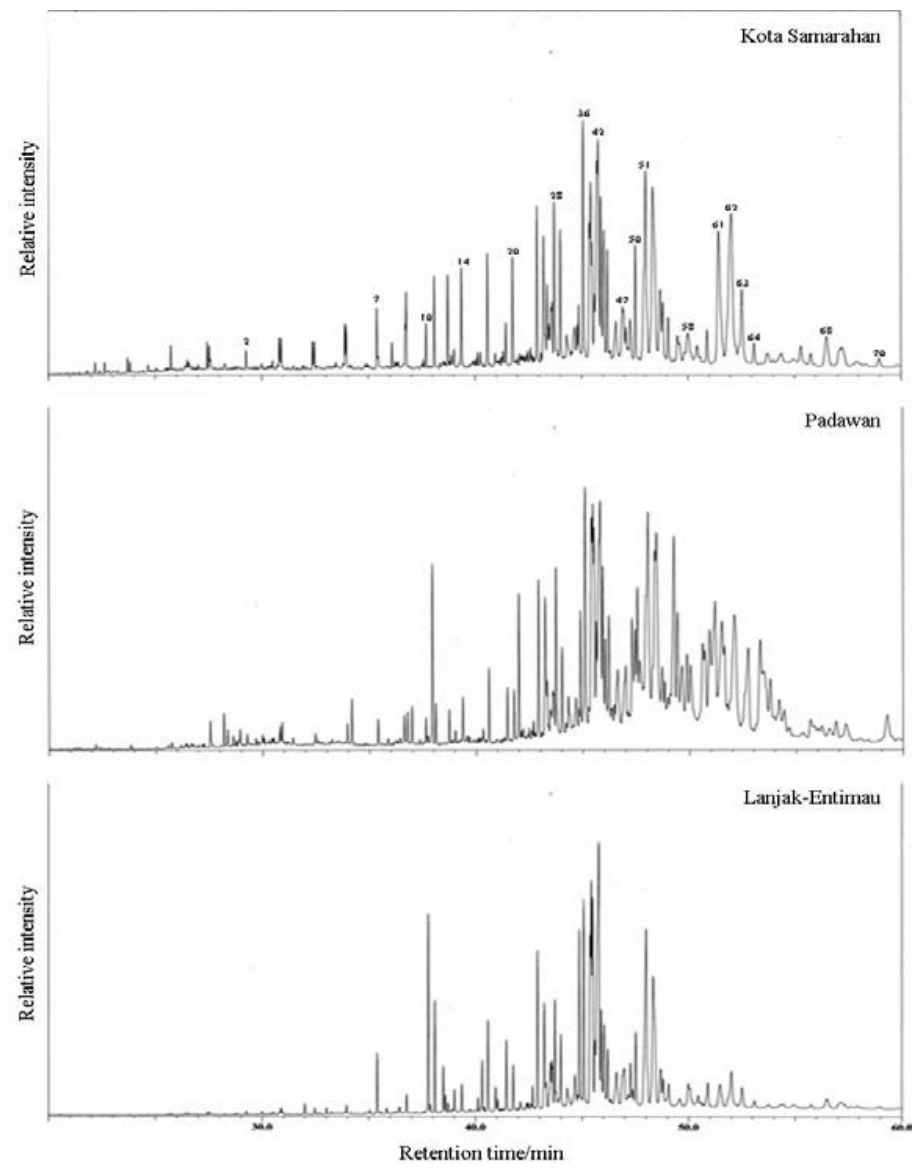

Figure 1. Total chromatogram of GC analysis for cuticular surface lipids of the Epilacnha indica from different localities. 
Table 1. $n$-alkanes identified in the cuticle of matured Epilacnha indica. The data listed the common hydrocarbons detected in all samples examined using GC/MS analysis.

\begin{tabular}{|c|c|c|c|c|c|c|}
\hline \multirow{2}{*}{ No. } & \multirow{2}{*}{$\begin{array}{l}\text { Retention } \\
\text { time }^{b}\end{array}$} & \multirow{2}{*}{$\begin{array}{c}\text { Formula } \\
\text { Compound }^{\mathrm{c}}\end{array}$} & \multirow{2}{*}{$\begin{array}{c}\text { Name of } \\
\text { Compound }^{\mathrm{d}, \mathrm{e}}\end{array}$} & $\begin{array}{c}\text { Kota } \\
\text { Padawan }^{\mathrm{a}}\end{array}$ & $\begin{array}{l}\text { Lanjak- } \\
\text { Entimau }^{a}\end{array}$ & $\begin{array}{c}\text { Kota } \\
\text { Samarahan }^{\mathrm{a}}\end{array}$ \\
\hline & & & & {$[$ Mean \pm Std. $]$} & {$[$ Mean \pm Std. $]$} & {$[$ Mean \pm Std. $]$} \\
\hline 1 & 27.458 & $\mathrm{C}_{18} \mathrm{H}_{38}$ & $n$-octadecane & $0.70 \pm 0.22$ & $0.16 \pm 0.02$ & $1.41 \pm 0.39$ \\
\hline 2 & 29.267 & $\mathrm{C}_{19} \mathrm{H}_{40}$ & $n$-pristane & $0.59 \pm 0.27$ & $0.25 \pm 0.02$ & $0.92 \pm 0.25$ \\
\hline 3 & 30.905 & $\mathrm{C}_{20} \mathrm{H}_{42}$ & $n$-eicosane & $0.87 \pm 0.34$ & $0.34 \pm 0.17$ & $1.67 \pm 0.75$ \\
\hline 4 & 32.470 & $\mathrm{C}_{21} \mathrm{H}_{44}$ & $n$-heneicosane & $0.59 \pm 0.43$ & $0.38 \pm 0.22$ & $1.44 \pm 0.25$ \\
\hline 5 & 33.965 & $\mathrm{C}_{22} \mathrm{H}_{46}$ & $n$-decosane & $0.65 \pm 0.25$ & $0.33 \pm 0.18$ & $2.31 \pm 0.38$ \\
\hline 6 & 35.401 & $\mathrm{C}_{23} \mathrm{H}_{48}$ & $n$-tricosane & $1.23 \pm 0.75$ & $5.17 \pm 0.72$ & $1.63 \pm 0.84$ \\
\hline 7 & 36.778 & $\mathrm{C}_{24} \mathrm{H}_{50}$ & $n$-tetracosane & $1.11 \pm 0.67$ & $0.95 \pm 0.29$ & $3.58 \pm 0.87$ \\
\hline 8 & 38.098 & $\mathrm{C}_{25} \mathrm{H}_{52}$ & $n$-pentacosane & $2.20 \pm 0.61$ & $10.62 \pm 1.19$ & $4.91 \pm 0.75$ \\
\hline 9 & 39.368 & $\mathrm{C}_{26} \mathrm{H}_{54}$ & $n$-hexacosane & $1.15 \pm 0.59$ & $1.92 \pm 0.64$ & $5.49 \pm 0.76$ \\
\hline 10 & 40.592 & $\mathrm{C}_{27} \mathrm{H}_{56}$ & $n$-heptacosane & $3.14 \pm 0.95$ & $8.36 \pm 1.14$ & $6.83 \pm 0.47$ \\
\hline 11 & 41.770 & $\mathrm{C}_{28} \mathrm{H}_{58}$ & $n$-octacosane & $2.42 \pm 0.76$ & $3.39 \pm 0.30$ & $6.61 \pm 0.37$ \\
\hline 12 & 42.910 & $\mathrm{C}_{29} \mathrm{H}_{60}$ & $n$-nonacosane & $8.56 \pm 0.52$ & $15.88 \pm 0.76$ & $9.27 \pm 0.57$ \\
\hline 13 & 44.011 & $\mathrm{C}_{30} \mathrm{H}_{62}$ & $n$-triacontane & $4.00 \pm 1.12$ & $6.29 \pm 0.69$ & $7.57 \pm 0.69$ \\
\hline 14 & 45.076 & $\mathrm{C}_{31} \mathrm{H}_{64}$ & $n$-hentriacontane & $16.86 \pm 0.53$ & $19.86 \pm 2.44$ & $15.47 \pm 1.71$ \\
\hline 15 & 46.213 & $\mathrm{C}_{32} \mathrm{H}_{66}$ & $n$-dotriacontane & $7.65 \pm 1.55$ & $7.08 \pm 0.43$ & $7.25 \pm 0.51$ \\
\hline 16 & 47.527 & $\mathrm{C}_{33} \mathrm{H}_{68}$ & $n$-tritriacontane & $11.93 \pm 1.10$ & $9.04 \pm 0.72$ & $8.03 \pm 0.67$ \\
\hline 17 & 49.103 & $\mathrm{C}_{34} \mathrm{H}_{70}$ & $n$-tetratriacontane & $4.40 \pm 1.76$ & $3.57 \pm 1.13$ & $4.74 \pm 0.56$ \\
\hline 18 & 50.991 & $\mathrm{C}_{35} \mathrm{H}_{72}$ & $n$-pentatriacontane & $14.43 \pm 1.79$ & $4.35 \pm 1.29$ & $4.85 \pm 0.90$ \\
\hline 19 & 53.153 & $\mathrm{C}_{36} \mathrm{H}_{74}$ & $n$-hexatriacontane & $10.75 \pm 1.27$ & $1.50 \pm 0.32$ & $2.90 \pm 0.56$ \\
\hline 20 & 55.768 & $\mathrm{C}_{37} \mathrm{H}_{76}$ & $n$-heptatriacontane & $2.45 \pm 0.84$ & $0.62 \pm 0.17$ & $1.78 \pm 0.18$ \\
\hline 21 & 59.001 & $\mathrm{C}_{38} \mathrm{H}_{78}$ & $n$-octatriacontane & $4.24 \pm 0.81$ & $0.00 \pm 0.00$ & $1.52 \pm 0.35$ \\
\hline
\end{tabular}

${ }^{a}$ Values are the averages for 18 samples of $E$. indica collected from three different localities.

${ }^{\mathrm{b}}$ Retention time correspond to the value in the range of -0.015 to +0.020 , which was used as a measure of acceptance on the samples data

${ }^{c}$ Formula given based on straight-chained alkanes, $\mathrm{C}_{\mathrm{n}} \mathrm{H}_{2 \mathrm{n}+2}$.

${ }^{\mathrm{d}}$ Compounds were determined from GC/MS analysis. The peaks that represent mean less than $0.05 \%$ were not included in the data table.

e The compounds' name were based on The Pherobase: Database of Insect Pheromones and Semiochemicals by El-Sayed (2013). 
Although this study did not included branched chain alkanes in quantitative analysis, qualitative examination on branched chain alkanes in samples collected from three different localities indicated that several compounds showed significant difference in their relative abundance. $3-\mathrm{MeC}_{24}, 5-\mathrm{MeC}_{25}$, $12 / 14-\mathrm{MeC}_{34}, 11-\mathrm{MeC}_{25}$ 13, 17-diMeC 35 and $11,15,23$-triMeC 35 are among branched chain alkanes detected abundantly at least at one of the localities. Furthermore, several unsaturated hydrocarbons including $1-\mathrm{C}_{19}$ ene, $1-\mathrm{C}_{20}$ ene, 1$\mathrm{C}_{21}$ ene, 1- $\mathrm{C}_{22}$ ene, $9-\mathrm{C}_{23}$ ene, $1-\mathrm{C}_{24} \mathrm{ene}$, and a few branched chain hydrocarbons such as 7mehtyalkane and 11-methylalkane were not detected at least in one of the localities.

$n$-alkanes from $\mathrm{C}_{18}$ to $\mathrm{C}_{38}$ were detected in 18 samples analyzed, with the exceptions of $n$ $\mathrm{C}_{37}$ compounds for Lanjak-Entimau. However, hydrocarbon compounds showed different concentration at different locality. Further examination on gas chromatogram of GC/MS revealed that $n$-alkanes were common for four replicates samples in each locality, but the mean relative proportions of several $n$-alkanes varied significantly. The shorter chain $n$ alkanes between $n-\mathrm{C}_{23}$ and $n-\mathrm{C}_{31}$ were the most abundant hydrocarbons in Lanjak- Entimau samples, while longer chain $n$-alkanes ranging from $n-\mathrm{C}_{33}$ to $n-\mathrm{C}_{38}$ were abundant in Kota Padawan samples (Figure 2).
Analysis of variance signified that there was a significant difference of proportions of $n$ alkanes between three different localities, except $n$-dotriacontane $\left(n-\mathrm{C}_{32}\right) \quad(\mathrm{F}=0.352, \mathrm{p}$ value $=0.713>0.05)$ and $n$-tetratriacontane $(n$ $\left.\mathrm{C}_{34}\right)(\mathrm{F}=0.930$, p-value $=0.430>0.05)$. However, $n$-hentriacontane $\left(n-\mathrm{C}_{31}\right)$ compound were not significant at $\mathrm{P}>0.01$, while other $n$-alkanes show significant different with $p$ value $<0.001$. The highest variance of $n$-alkanes between the three different localities was $n-\mathrm{C}_{29}$, followed by $n-\mathrm{C}_{36}$ at $95 \%$ confident interval with $\mathrm{F}$ values were 160.638 and 147.196 , respectively.

Significant different of certain $n$-alkanes between Lanjak-Entimau and Kota Samarahan revealed with Tukey's HSD test (Honestly Significantly Different), that is hydrocarbon composition at lower chain length $n$-alkanes ranging from $n-\mathrm{C}_{18}$ to $n-\mathrm{C}_{26}$ with $\mathrm{p}$-value $<0.01$. In contrast, longer chain length $n$ alkanes from $n-\mathrm{C}_{35}$ to $n-\mathrm{C}_{38}$ showed a significant different between Kota Padawan and Lanjak-Entimau, with exception of $n-\mathrm{C}_{23}$ and $n-\mathrm{C}_{25}$. Comparison between Kota Samarahan and Kota Padawan samples revealed the significant different in hydrocarbon composition for even-numbered carbon $n$-alkanes ranging from $n-\mathrm{C}_{18}$ to $n-\mathrm{C}_{38}$ except $n-\mathrm{C}_{32}$ and $n-\mathrm{C}_{34}$. Several odd-numbered carbon $n$-alkanes such as $n-\mathrm{C}_{25}, n-\mathrm{C}_{27}, n-\mathrm{C}_{33}$

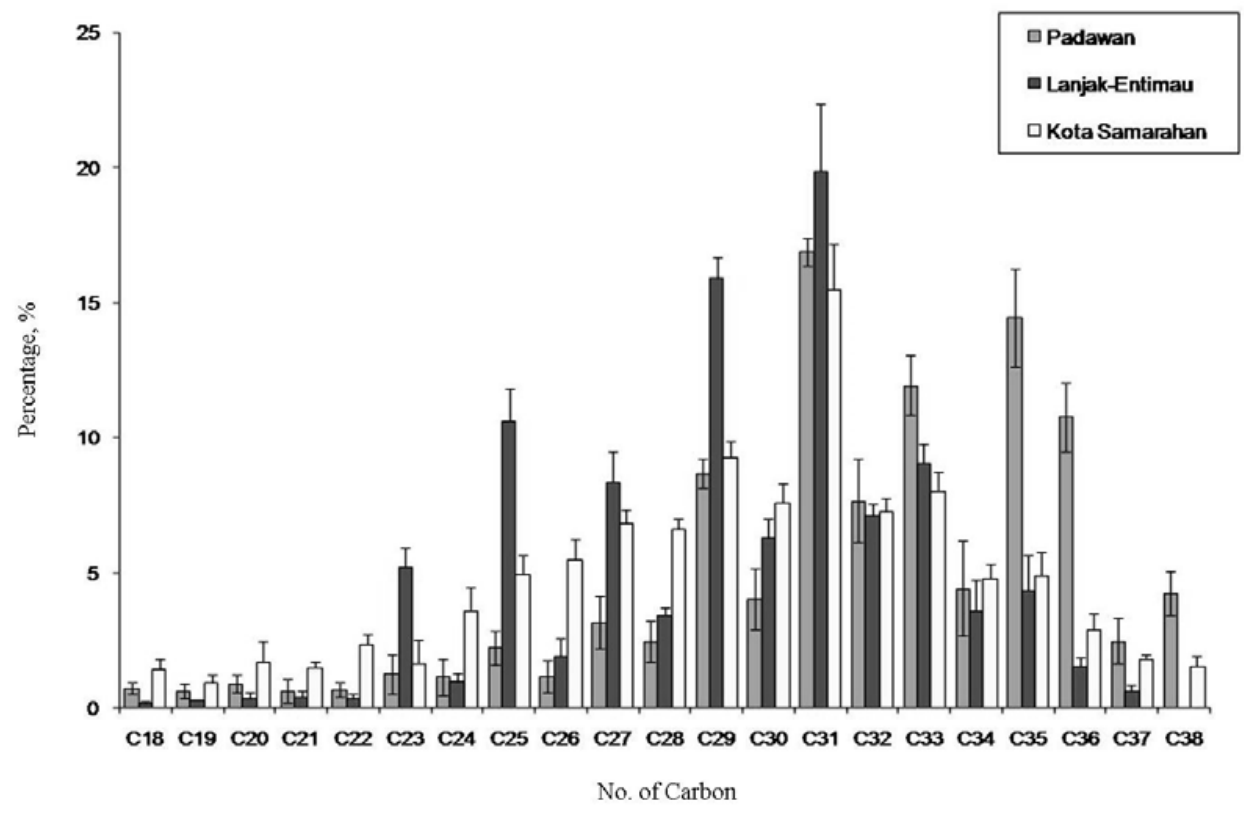

Figure 2. Amounts (\%) of $n$-alkanes extracted from Epilacnha indica collected from three different localities $(\mathrm{n}=18)$. Error bars represent standard deviations. 
and $n-\mathrm{C}_{35}$ also showed significant difference in composition between Kota Samarahan and Kota Padawan.

A discriminant function analysis (DFA) evaluates the pattern of $n$-alkanes abundance between individuals. All variance in the data set was explained by the first two discriminant functions. More than $65 \%$ was contributed by the function 1 , while $35.2 \%$ of variance explained by function 2. Examination on components contributing to the differentiation of localities showed that $n-\mathrm{C}_{29}, n-\mathrm{C}_{33}$ and $n-\mathrm{C}_{36}$ were important in discriminating three different localities although other compounds were found to be significantly different through analysis of variance. DFA successfully classified all samples into three correct groups in $100 \%$ of cases, with cross-validation resulted in an error of $7.7 \%$. The pattern of segregation of the populations is graphically represented in Figure 3. This result indicated that insects from a single population are generally similar to each other. Quantitative data from cuticular hydrocarbons of E. indica can discriminate samples into their respective group even from small numbers of samples.

Similar to that of DFA, four (4) samples out of six (6) samples from each locality were also used in cluster analysis. Cluster analysis successfully separated the samples into 3 centroid groups. Each centroid group consists of all samples from the same sampling sites (locality). Group 1 showed the samples collected from Kota Samarahan, while group 2 and 3 represent samples from Lanjak-Entimau and Kota Padawan, respectively (see Figure 4). The dendrogram had been successfully constructed using $n$-alkanes proportions. The result implied that the samples examined were placed in respected group. Individuals from each location were grouped in the range of 2.10 - $9.16 \%$ differences, with average of $43 \%$ different reflected between localities. Comparison between Kota Samarahan-LanjakEntimau samples and Kota Samarahan-Kota Padawan samples showed similarity up to $71.8 \%$ and $55.5 \%$, while Kota PadawanLanjak-Entimau had only $39.9 \%$ similarity. The finding reveals the potential of cuticular hydrocarbons profile to separate subpopulations of species.

\section{DISCUSSION}

Distributions of cuticular hydrocarbons in $E$. indica are typical of those commonly found in insects, and there was no unusual compounds detected. No dominant hydrocarbons exceeding $10 \%$ of the total hydrocarbons concentration were detected. This profile complimented the report by Kosaki and Yamaoka (1996). However, in their study, they found hydrocarbon ranges from $\mathrm{C}_{23}$ to $\mathrm{C}_{35}$ in $E$. indica. While in this study, the distribution of cuticular hydrocarbon is in the range of $\mathrm{C}_{18}$ to $\mathrm{C}_{38}$. It was probably due to the population from tropical region producing longer carbon chain length to prevent desiccation compare to those in temperate region.

The occurrence of variation in cuticular hydrocarbon compositions of insects was pronounced from various levels. Several studies were also reported that the variation in distribution patterns of cuticular hydrocarbon have shown among individuals of the species (Brown et al., 1998; Chapman et al., 1995). This study found that $E$. indica samples collected from the forests containing simpler hydrocarbon pattern than samples collected in housing or industrial areas. This shows that differences in micro-environment have influenced the composition and proportion of insect cuticular hydrocarbon. It was suggested that the degree of direct exposure to sunlight and level of humidity could be part of the factor that contribute to the variation between subpopulation.

This study observed that the $n$-alkanes were identical in particular location for each individual population, but the relative concentrations of several $n$-alkanes varied significantly. The differences in $n$-alkanes proportion within population are relatively small where greater differences were observed among different geographical population. The minor quantitative differences among same compound were also shown in other insects (Brown et al., 2000). It showed that the differences are from quantitative variation among the same components, although there are qualitative differences among branched alkanes (excluded in the statistical analysis). 


\section{Canonical Discriminant Functions}

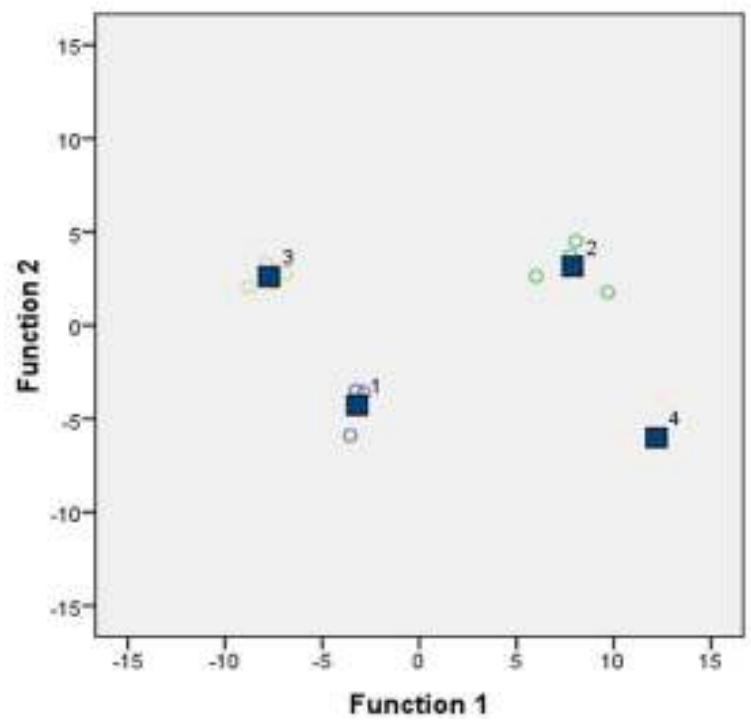

GROUP

Oi Padawan

2 Lanjak-Entimau

3 Kota Samarahan

4 Out Group

Group Certroid

unction 1

Figure 3. DFA displaying the relative position of 12 samples from three different sampling locations with an adult sample used as out group in the analysis.

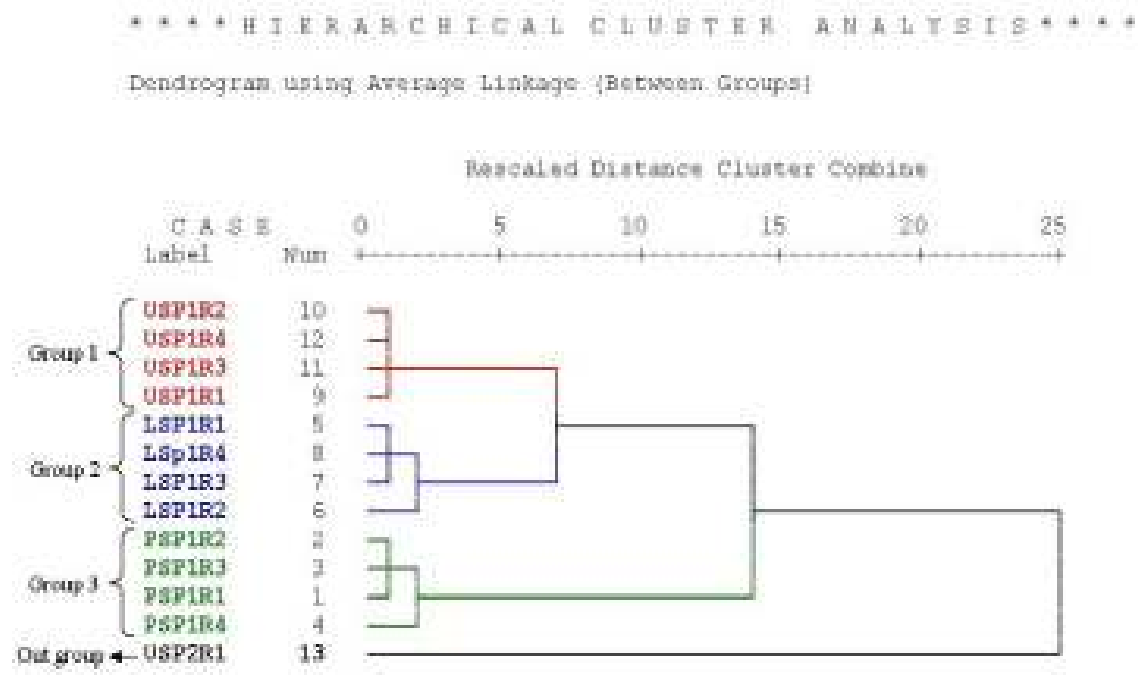

Figure 4. A tree diagram (dendrograms) from a cluster analysis using the maximum $21 n$-alkanes detected in each sample. The samples were collected from three different sampling locations. USP1R1-USP1R4, LSP1R1LSP1R4 and PSP1R1-PSP1R4 represent samples of E. Indica from Kota Samarahan, Lanjak-Entimau and Kota Padawan, respectively.

Three populations namely Kota Samarahan, Kota Padawan and Lanjak-Entimau, were remarkably different from one another. It seems that the quantitative differences among population of E. indica derive from microenvironment factor since each sampling site representing different type of microenvironment. Thus, it affects the level of 
evaporation, whereby evaporation of water through cuticle can be expected to be lower at higher humidity or at low temperature. Therefore, smaller amount of cuticular hydrocarbons may be needed to protect insects from desiccation. Noorman and Den Otter (2002) stated that relative humidity and temperature have a temporary effect on the composition of insects' cuticular hydrocarbons.

The result of discriminant analysis also suggests that the hydrocarbon differences in ladybirds' $E$. indica may be due to geographical isolation. Discriminant function analysis (DFA) revealed that cuticular hydrocarbons compounds can be used to identify and group individuals into their own population. Individual from same population would share similar hydrocarbon compounds, but insects collected from different locations posses different cuticular hydrocarbons composition. The variable in cuticular hydrocarbon profiles within a single species has raised questions regarding the ecological meaning of this variability (Howard, 1993). Anyanwu et al. (2000) proposed that the patterns of segregation or isolation in hydrocarbons adds to the distinct esterase enzyme characteristic and chromosomal differences, thus providing further information on the differences between the population of species studied.

It may be concluded that cuticular hydrocarbons are primarily genetic control, but the production are affected by environmental factors as a form of adaptation (Frentiu \& Chenowelth, 2010). Chapman et al. (2000) stated that such variations among individuals occurred within the limit of the character or profile of cuticular hydrocarbon in the species. However, the variations in cuticular hydrocarbon profiles, either in type of compounds or relative concentrations, between subpopulation are still not fully understood. Several researchers such as Brown et al. (1998) and Anyanwu et al. (2000) suggested that these differences represent geographical variation, and could play as future speciation mechanisms (Phillips et al., 1990). For example, geographic population was the major determinant of variation in the melting points of cuticular lipids of grasshoppers (Gibbs et al., 1991). While, Haverty et al. (2000) revealed that there is a seasonal variation in the proportion of several hydrocarbons which reflected the behavior of the species.

Though quantitative differences suggested that some genetic variation among geographical variation does exist, the present of sibling species or subspecies may not be sufficiently pronounced. The differences were also found in worm fly Chrysoma sp. (Brown et al., 1998), cockroach Macropanesthia sp. (Brown et al., 2000), grasshopper Schistocerca spp. (Chapman et al., 2000), wasps Polistes spp. (Dani, 2006) and others. According to Brown et al. (2000), differences in hydrocarbon composition within populations are relatively small, while the differences among different geographical population showed much greater variation. However, the status of quantitative differences, based on proportion of $n$-alkanes compounds between locations, which is up to $43 \%$ remains unclear.

\section{CONCLUSION}

Variation does occur in the relative abundance of the hydrocarbons in the cuticular lipids of a single species of ladybird beetle. The differences in micro-environment have influenced the composition and proportion of insect cuticular hydrocarbon. If cuticular hydrocarbons are used as a component of taxonomic studies on ladybird beetles, conclusions certainly cannot be based on single specimens, or even on a number of specimens from a single habitat. Therefore, studies on specimens of known taxa from a variety of habitats could draw meaningful conclusions about the usefulness of cuticular hydrocarbons in insect taxonomy, particularly on species complex.

\section{ACKNOWLEDGEMENT}

The authors acknowledge FRGS grant, FRST/01(06)/611/2006(44), for funding this project.

\section{REFERENCES}

Abdalla, F.C., Jones, G.R., Morgan, E.D., \& Cruz-landim, C. (2003). Comparative study of the cuticular hydrocarbons composition of Melipona bicolor (Lepeletier, 1836) 
(Hymenoptera, Meliponini) worker and queens. Genetic and Molecular Research, 2 (2):191-199.

Anyanwu, G.I., Molyneux, D.H., \& Phillips, A. (2000). Variation in cuticular hydrocarbons among strains of the Anopheles gambiae sensu stricto by analysis of cuticular hydrocarbons using gas liquid chromatography of larvae. Annuals of Tropical Medicine and Parasitology, 95 (3):295-300.

Arsene, C., Schulz, S., \& Van Loon, J.J.A. (2002). Chemical polymorphism of the cuticular lipids of the cabbage white Pieris rapae. Journal of Chemical Ecology, 28(12):37-42.

Brown, W.V., Rose, H.A., \& Lacey, M.J. (1997). The cuticular hydrocarbons of the soil burrowing cockroach Geoscapheus dilatatus (Saussure) (Blattodea: Blaberidae: Geoscapheinae) indicate species dimorphism. Comparative Biochemistry and Physiology, Part B 118 (3):549-562.

Brown, W.V., Morton, R., Lacey, M.J., Spradbery, J.P., \& Mahon, R.J. (1998). Identification of the Geographical source of adults of Old World Screw Fly, Chrysomya bezziana Villeneuve (Diptera: Calliphoridae), by Multivariate Analysis of cuticular hydrocarbons. Comparative Biochemistry and Physiology, Part B 119 (2):391-399.

Brown, W.V., Rose, H.A., Lacey, M.J., \& Wright, K. (2000). The cuticular hydrocarbons of the giant soil-burrowing cockroach Macropanesthia rhinoceros Saussure (Blattodea: Blaberidae: Geoscapheinae): Analysis with respect to age, sex and location. Comparative Biochemistry and Physiology, Part B 127 (3):261-277.

Chapman, R.F., Espelies, K.E., \& Swords, G.A. (1995). Use of cuticular lipids in grasshopper taxonomy: A study of variation in Schistocerca shoshone (Thomas). Biochemical Systematics and Ecology, 23 (4):383-398.

Chapman, R.F., Espelies, K.E., \& Peck, S.B. (2000). Cuticular hydrocarbons of grasshoppers from the Galapagos Islands,
Ecuador. Biochemical Systematics and Ecology, 28 (6):579-588.

Dani, F.R. (2006). Cuticular lipids as semiochemicals in paper wasps and other social insects. Annales Zoologici Fennici, 43:500-514.

El-Sayed, A.M. (2013). The Pherobase: Database of Insect Pheromones and Semiochemicals. Available from http://www.pherobase.com. Access date: 12 August 2013.

Gibbs, A., Mousseau, T.A., \& Crowe, J.H. (1991). Genetic and acclimatory variation in biophysical properties of insect cuticle lipids. Proceeding of the National Academy of Science, 88 (16):7257-7260.

Haverty, M.I., Page, M., Thorne, B.L., \& Escoubas, P. (1991). Cuticular hydrocarbons: Species and population level discrimination in termites. United States Forest Service General Technical Report PSW, 128:15-23.

Haverty, M.I., Grace, J.K., Nelson, L.J., \& Yamamoto, R.T. (1996). Intercaste, intercolony, and temporal variation in cuticular hydrocarbons of Coptotermes formosanus Shiraki (Isoptera: Rhinotermitidae). Journal of Chemical Ecology, 22(10):1813-1834.

Haverty, M.I., Getty, G.M., Copren, K.A., \& Lewis, V.R. (2000). Size and dispersion of colonies of Reticulitermes spp. (Isoptera: Rhinotermitidae) in a wild land and a residential location in northern California. Environmental Entomology, 29(2):241-249.

Howard, R.W. (1993). Cuticular hydrocarbons and chemical communication. In: D.W. Stanley-Samuelson, \& D.R Nelson, (Eds.), Insect Lipids: Chemistry, Biochemistry and Biology. Lincoln, USA: University of Nebraska Press. Pp179-226.

Juarez, M.P. \& Fernandez, G.C. (2007). Cuticular hydrocarbons of triatomines. Comparative Biochemistry and Physiology, Part A, 147(3):711-730.

Kosaki, A. \& Yamaoka, R. (1996). Chemical composition of footprint and cuticular lipids of three species of lady beetles. Japan Journal of Applied Entomology and 
Zoology, 40:47-53.

Lapointe, S.L, Hunter, W.B., \& Alessandro, R.T. (2004). Cuticular hydrocarbons on elytra of the Diaprepes root weevil Diaprepes abbreviatus (Coleoptera: Curculionidae). Agricultural and Forest Entomology, 6(4):251-257.

Lockey, K.H. (1988). Lipids of the insects' cuticle: Origin, composition and function. Comparative Biochemistry and Physiology, Part B 89(4):595-645.

Martin, S. \& Drijfhout, F. (2009). A review of ant cuticular hydrocarbons. Journal of Chemical Ecology, 35(10):1151-1161.

Nelson, D.R. \& Charlet, L.D. (2003). Cuticular hydrocarbons of sunflower beetles, Zygogramma exclamationis. Comparative Biochemistry and Physiology, Part B, 102(3):451-470.

Noorman, N. \& Den Otter, C.J. (2002). Effect of relative humidity, temperature, and population density on production of cuticular hydrcarbons in housefly Musa domestica L. Journal of Chemical Ecology, 28(9):1819-1829.

Nunes, T.M., Morgan E.D., Drijfhout, F.P., \& Zucchi, R. (2010). Caste-specific cuticular lipids in the stingless bee Friesella schrottkyi. Apidologie, 41(5):579-588.

Page, M., Nelson, L.J., Haverty, M.I., \& Blomquist, G.J. (1990). Cuticular hydrocarbons chemotaxonomic character for bark beetles: Dendroctonus ponderosae, $D$. jeffreyi, D. brevicomis, and D. frontalis (Coleooptera: Scolytidae). Annual Meeting of the Entomological and Society of America, 83:892-901.

Phillips, A., Le Pont, F., Desjeux, P., Broomfield, G., \& Molyneux, D.H. (1990). Separation of Psychodopygus carrerai carrerai and P. yucumensis (Diptera: Psychodidae) by gas chromatography of cuticular hydrocarbons. Acta Tropica, 47(3):145-149.
Soliday, C.L., Blomquists, G.L., \& Jackson, L.L. (1974). Cuticular lipids of insects. VI. Cuticular lipids of the grasshoppers Melanoplus sanguinipes and Melanoplus packardii. Journal of Lipid Research, 15:399-405.

Takematsu, Y. \& Yamaoka, R. (1997). Taxonomy of Gzyptotermes (Isoptera: Kalotermitidae) in Japan with reference to cuticular hydrocarbons analysis as chemotaxonomic characters. Esakia: Occasional papers of the Hikosan Biological Laboratory in Entomology, 37:114.

Tung, V.W. (1983). Common Malaysian Beetles. Kuala Lumpur, Malaysia: Longman Publication. Pp.142.

Whitlow, V.V.S. (2003). Recognition in burying beetles (Nicrophorus spp., Silphidae, Coleoptera). University of der Albert Ludwigs, Freiburg im Breisgau, Germany. Unpublished PhD Thesis.

Wilgenburg, E.V., Symonds, M.R.E., \& Elgar, M.A. (2011). Evolution of cuticular hydrocarbon diversity in ants. Journal of Evolution Biology, 24:1188-1198.

Woodrow, R.J., Grace, J.K., Nelson, L.J., \& Haverty, M.I. (2000). Modification of cuticular hydrocarbons of Cryptotermes brevis (Isoptera: Kalotermitidae) in response to temperature and relative humidity. Journal of Physiololgical and Chemical Ecology, 29(6):1100-1107. 